\title{
RANCANG BANGUN PROTOTYPE PENJEMUR PAKAIAN OTOMATIS BERBASIS MIKROKONTROLER ATMEGA8535
}

\author{
Eko Rismawan, Sri Sulistiyanti, Agus Trisanto \\ Jurusan Teknik Elektro Fakultas Teknik Universitas Lampung \\ ekorismawan@rocketmail.com,Winantya@unila.ac.id, at@unila.ac.id.
}

\begin{abstract}
Abstrak
Saat ini penerapan sensor untuk memudahkan pekerjaan manusia semakin meningkat. Salah satunya ialah penggunaan sensor hujan yang di aplikasikan pada jemuran pakaian. Mikrokontroler akan menerima sinyal dari sensor tersebut, lalu memberikan perintah pada motor driver untuk memerintahkan motor DC berputar kekiri atau kekanan. Arah putaran motor DC di tentukan oleh perintah langsung dari Mikrokontroler. Mikrokontroler sebagai otak untuk memerintah, sangat di andalkan agar tidak salah dalam menjalankan motor DC. Jemuran mampu untuk bergerak sejauh kurang lebih 1,5 meter. Tujuannya adalah motor dapat menggulung rel jemuran, agar baju atau jemuran tidak menjadi basah karena kehujanan. Setelah jemuran masuk maka mikrokontroler akan memerintahkan blower untuk hidup.
\end{abstract}

Kata Kunci : Sensor Hujan, Driver Motor, Motor DC

\begin{abstract}
Currently the application of sensors to facilitate human work is increasing. One is the use of rain sensors applied in clothes horse. Microcontroller will receive the signal from the sensor, and gave the command to the motor driver for DC motor command rotates left or right. DC motor rotation direction is determined by the direct orders of the Microcontroller. Microcontroller as the brain to rule, so in order not to rely on any of the DC motor running. Clothesline able to move as far as approximately 1.5 meters. The goal is to roll the rail motors clothesline, clothesline or clothes that do not become wet because of the rain. Once the clothes horse entered the microcontroller will tell the blower to live.
\end{abstract}

Keywords : Rain Sensor, Motor Drivers, DC Motor

\section{PENDAHULUAN}

\subsection{Latar Belakang}

Sistem kendali secara otomatis di bidang ilmu pengetahuan dan teknologi belakangan ini berkembang dengan pesat. Dengan adanya kemajuan di bidang ilmu pengetahuan dan teknologi menghasilkan inovasi baru yang berkembang menuju lebih baik. Hal ini dapat dilihat jangkauan aplikasinya mulai dari rumah tangga hingga peralatan yang canggih.

Menjemur pakaian adalah salah satu kegiatan yang sering dilakukan didalam kehidupan rumah tangga, dan biasa kita lihat menjemur pakaian sering kita tinggal bepergian, sehingga kita tidak sempat lagi untuk mengangkat jemuran pada waktu akan turun hujan. Pemanasan global yang sekarang ini sedang terjadi menyebabkan perubahan cuaca yang sangat sulit di tebak, sehingga kadang terjadi perubahan cuaca secara tiba-tiba dari panas menjadi hujan ataupun sebaliknya sehingga kegiatan menjemur pakaian sangat terganggu.

Untuk mengatasi masalah tersebut perlu adanya sistem kontrol otomatis, dengan cara membuat sistem jemuran otomatis. Dalam perancangan implementasi sistem jemuran otomatis, masalahmasalah yang dipecahkan adalah meliputi sistem pengendali jemuran, arsitektur perangkat keras, meliputi : perangkat elektronik dan mekanik dari keterangan diatas maka penulis padukan untuk merealisasi jemuran otomatis yang efektif dan efisien, dalam kesempatan penyusunan tugas akhir dengan judul Rancang bangun prototype penjemur 
pakaian otomatis berbasis mikrokontroler Atmega8535.

\subsection{Tujuan Penelitian}

Tujuan yang ingin dicapai dari penelitian ini adalah:

Membuat sebuah alat yang dapat membantu meringankan pekerjaan rumah tangga khususnya dalam kegiatan menjemur pakaian.

\subsection{Manfaat Penelitian}

Dapat mendesain sebuah alat yang dapat membantu meringankan pekerjaan rumah tangga khususnya dalam kegiatan menjemur pakaian yang dikendalikan oleh mikrokontroler.

\subsection{Rumusan masalah}

Perubahan cuaca yang secara tiba-tiba terkadang menyebabkan pekerjaan rumah tangga yaitu menjemur pakaian sering terganggu, sehingga perlu adanya sebuah alat yang dapat membantu mengatasi masalah rumah tangga tersebut.

\subsection{Batasan Masalah}

Batasan-batasan masalah yang melingkupi penelitian ini antara lain:

1. Tidak membahas masalah perubahan cuaca.

2. Tidak membahas keadaan angin.

\subsection{Hipotesis}

Penjemur pakaian otomatis sangatlah membantu dalam meringankan pekerjaan rumah tangga. Terutama pada aktifitas menjemur pakaian yang masih basah, karena dengan menggunakan alat ini diharapkan dapat mempermudah pekerjaan menjemur pakaian.

\section{TINJAUAN PUSTAKA}

\subsection{Pendahuluan}

Perubahan iklim global yang terjadi pada saat ini menyebabkan kondisi cuaca yang susah ditebak, hal ini menyebabkan perubahan cuaca yang secara tiba-tiba dari panas ke hujan ataupun sebaliknya. Akibatnya banyak aktifitas yang bisa terganggu akibat hal tersebut, diantaranya adalah kegiatan menjemur pakaian.

Menjemur pakaian adalah salah satu kegiatan yang sering dilakukan didalam kehidupan rumah tangga, dan biasa kita lihat menjemur pakaian sering kita tinggal bepergian, sehingga kita tidak sempat lagi untuk mengangkat jemuran pada waktu akan turun hujan. Untuk mengatasi masalah tersebut perlu adanya sistem kontrol otomatis, dengan cara membuat sistem jemuran otomatis. Dalam perancangan implementasi sistem jemuran otomatis, masalah-masalah yang dipecahkan adalah meliputi sistem pengendali jemuran, arsitektur perangkat keras, meliputi: perangkat elektronik dan mekanik.

Penggunaan alat penjemur pakaian otomatis ini akan sangat membantu aktifitas rumah tangga, terutama pada saat kita menjemur pakaian. Karena dengan menggunakan alat ini kita tidak perlu repot untuk mengangkat jemuran pada saat turun hujan, karena alat ini akan mendeteksi adanya indikasi apabila akan turun hujan.

\subsection{Dasar Sistem Kendali}

Sistem kendali atau sistem kontrol merupakan suatu sistem yang keluarannya atau outputnya dikendalikan pada suatu nilai tertentu atau untuk merubah beberapa ketentuan yang telah ditetapkan dari masukan atau input ke sistem. Untuk merancang suatu sistem yang dapat merespon perubahan tegangan dan mengeksekusi perintah berdasarkan situasi yang terjadi, maka diperlukan pemahaman tentang sistem kendali (controll system). Sistem kendali merupakan suatu kondisi dimana sebuah perangkat (device) dapat di kontrol sesuai dengan perubahan situasi.

\subsection{Mikrokontroler ATmega 8535}

Mikrokontroler adalah suatu keping IC dimana terdapat mikroprosesor dan memori program (ROM) serta memori serbaguna $(R A M)$, bahkan ada beberapa jenis mikrokontroler yang memiliki fasilitas $A D C, P P L, E E P R O M$ dalam suatu kemasan. Penggunaan mikrokontroler dalam bidang kontrol sangat luas dan popular. Ada beberapa vendor yang membuat mikrokontroler diantaranya Intel, Microchip, Winbond, Atmel, Philips, Xemics dan lain-lain buatan Atmel.

Mikrokontroler ATmega8535 merupakan generasi AVR ( Alf and Vegard's Risk processor). Mikrokontroler AVR memiliki arsitektur RISC (Reduced Instruction Set Computing) 8 bit, dimana semua instruksi dalam kode 16-bit (16-bit word) dan sebagian besar instruksi dieksekusi dalam 1 (satu) siklus clock. AVR menjalankan sebuah instruksi komponen eksternal dapat dikurangi. Mikrokontroler $A V R$ didesain menggunakan arsitektur Harvard, di mana ruang dan jalur bus bagi memori program dipisahkan dengan memori data. Dalam pemrogramannya mikrokontroller ATmega8535 ini 
menggunakan 2 bahasa program yakni, dengan bahasa $\mathrm{C}$ dan bahasa assembly.

\subsubsection{Arsitektur Mikrokontroller ATmega8535}

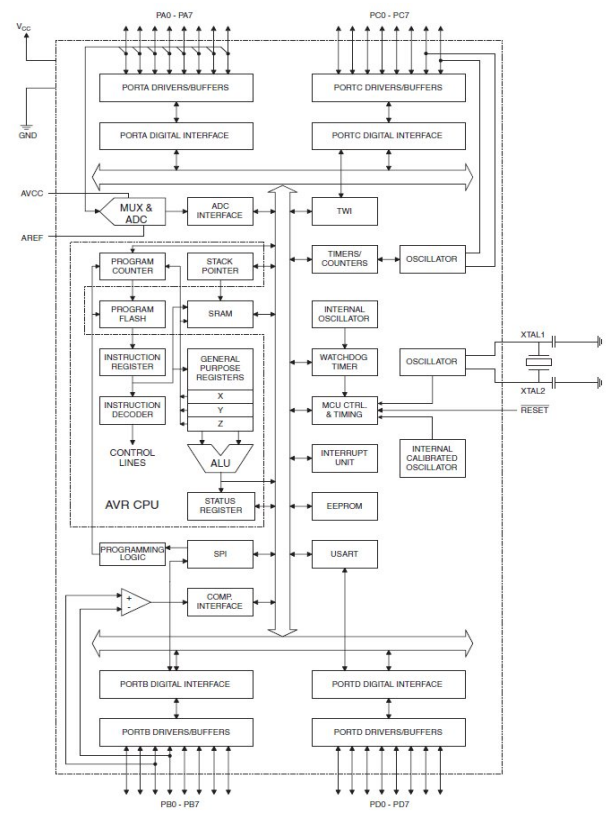

Gambar 2.1. Blok Diagram Fungsional ATmega8535

Dari Gambar 2.1 dapat dilihat bahwa ATmega8535 memiliki bagian sebagai berikut:

a. Saluran $I / O$ sebanyak 32 buah, yaitu PortA, Port B, Port C, dan Port D.

b. $A D C 10$ bit sebanyak 8 saluran.

c. Tiga buah Timer/Counter dengan kemampuan pembanding

d. $\quad C P U$ yang terdiri atas 32 buah register.

e. Watchdog Timer dengan osilator internal.

f. SRAM sebesar 512 byte.

g. Memori Flash sebesar $8 \mathrm{~Kb}$ dengan kemampuan Read While Write.

h. Unit interupsi internal dan eksternal.

i. Port antarmuka SPI.

j. EEPROM (Electrically Erasable Programmable Read Only Memori) sebesar 512 byte yang diprogram saat operasi.

k. Antarmuka komparator analog.

1. Port USART untuk komunikasi serial dengan kecepatan maksimal 12,5 Mbps.

m. Sistem mikroprosesor 8 bit berbasis RISC dengan kecepatan maksimal $16 \mathrm{MHz}$.

\subsection{Motor DC}

Rel jemuran digerakan dengan menggunakan motor $D C$ yang dipasang pada ujung rel jemuran. Pemilihan motor gear $d c$ didasarkan pada putaran dan torsi yang lebih besar dibandingkan dengan motor stepper atau motor servo, juga didasarkan atas ketersediaan di pasaran selain harga murah juga banyak variasinya.

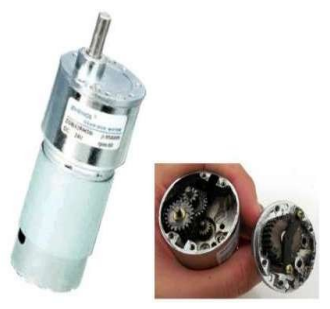

Gambar 2.2. Motor DC With Gearbox

\subsection{Motor Driver}

Motor gear $d c$ tidak dapat dikendalikan secara langsung oleh mikrokontroler, karena kebutuhan arus yang besar sedangkan keluaran arus dari mikrokontroler sangat kecil. Motor driver merupakan alternatif yang dapat digunakan untuk menggerakkan motor dc.

\subsection{LCD (Liquid Crystal Display)}

$L C D$ merupakan suatu jenis penampil (display) yang menggunakan Liquid Crystal sebagai media refleksinya. $L C D$ juga sering digunakan dalam perancangan alat yang menggunakan mikrokontroler. $L C D$ dapat berfungsi untuk menampilkan suatu nilai hasil sensor ,menampilkan teks, atau menampilkan menu pada aplikasi mikrokontroler. Tergantung dengan perintah yang ditulis pada mikrokontroler.

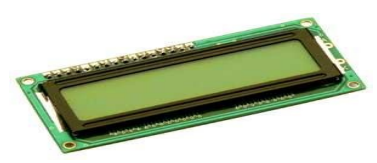

Gambar 2.3. LCD 2 x 16 Karakter

2.7 Saklar Microswitch 
Saklar microswitch merupakan salah satu jenis saklar jenis pushbuttom yang mempunyai sensitifitas cukup tinggi. Dalam pembuatan alat ini saklar microswitch digunakan sebagai penyambung inputan ground pada rangkaian untuk memberikan perintah stop pada putaran motor.

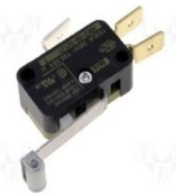

Gambar 2.4. Saklar Microswitch

\section{METODE PENELITIAN}

\subsection{Waktu dan Tempat}

Penelitian dan perancangan tugas akhir dilakukan di Laboratorium Terpadu Teknik Elektro Universitas Lampung dilaksanakan mulai bulan April 2012 sampai dengan September 2012.

\subsection{Alat dan Bahan.}

Alat dan bahan yang digunakan dalam penelitian yaitu:

a. Instrumen dan komponen Elektronika yang terdiri atas:

1. Multitester

2. Transformator

3. Motor DC

4. Transistor

5. Resistor

6. Kipas

7. Dioda

8. LED

9. Cristal $11,0592 \mathrm{MHz}$

10. LCD $2 \times 16$

11. IC Mikrokontroler ATMega8535

12. IC 7805

13. IC 7812

14. Relay $12 \mathrm{~V}$

15. Saklar Microswitch

b. Perangkat kerja yang terdiri atas:

1. Komputer

2. Power supply

3. Downloader AVR

4. Papan projek (Project Board)

5. Bor PCB

6. Solder
7. Kabel penghubung

8. Header Pin

c. Komponen bantu yang terdiri atas:

1. Papan plastik mika (Accrilyc)

2. Rel Jemuran

3. Rumah Jemuran

4. PCB

5. Feritklorit

6. Timah

\subsection{Spesifikasi Rancangan Alat}

Spesifikasi alat yang akan dibuat adalah sebagai berikut :

1. Menggunakan Mikrokontroler ATMega8535 sebagai pengendali.

2. Menggunakan $L C D 2 \times 16$ untuk menampilkan kondisi cuaca yang sedang terjadi.

3. Sensor hujan yang digunakan sebagai alat untuk pendeteksi turunnya hujan.

4. Motor $D C$ yang digunakan untuk menggerakan rel jemuran keluar masuk ruangan. Motor $D C$ yang digunakan mempunyai spesifikasi sebagai berikut :

a. Tegangan Maksimal 12 Volt DC

b. Output rpm 322

c. Torsi Maksimal $9 \mathrm{~kg}$

d. Gear Ratio $1: 31$

5. Satu set jemuran yang terdiri dari beberapa bagian yaitu :

a. Satu buah rel jemuran dengan panjang 2 meter

b. Tiang penyangga jemuran dengan tinggi 1,25 meter

c. Tempat untuk menggantungkan jemuran yang sudah dimodifikasi

d. Rumah jemuran yang berfungsi untuk menyimpan jemuran saat pada saat turun hujan dengan ukuran : Panjang 1 meter, Tinggi 1,5 meter dan Lebar $85 \mathrm{~cm}$

6. Dua buah Pulley yang digunakan untuk menggulung tali penggerak rel jemuran.

7. Dua buah saklar Microswitch yang digunakan sebagai pull-up.

\subsection{Prosedur Kerja.}

Langkah kerja dalam tugas akhir ini meliputi:

1. Studi literature

2. Penentuan spesifikasi rancangan

3. Perancangan perangkat keras/Hardware

4. Perancangan perangkat lunak

5. Pembuatan alat

6. Pengujian alat 
Diagram alir prosedur kerja dapat dilihat pada gambar 3.1 berikut:

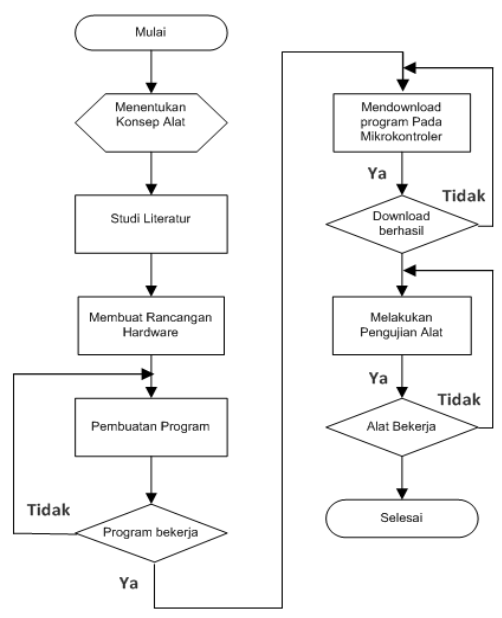

Gambar 3.1.Diagram Alir Pengerjaan Tugas Akhir

\subsubsection{Studi Literatur}

Dalam studi literatur dilakukan pencarian informasi mengenai segala sesuatu yang berkaitan dengan penelitian ini, diantaranya adalah:

a. Karakteristik komponen-komponen yang akan digunakan serta prinsip kerjanya.

b. Karakteristik dan spesifikasi motor listrik yang akan digunakan.

c. Cara kerja dan pemrograman mikrokontroler ATMega8535.

d. Cara kerja sensor yang akan digunakan.

\subsubsection{Penentuan Spesifikasi Rancangan}

Secara garis besar sistem pada tugas akhir ini adalah seperti gambar 3.2 berikut:

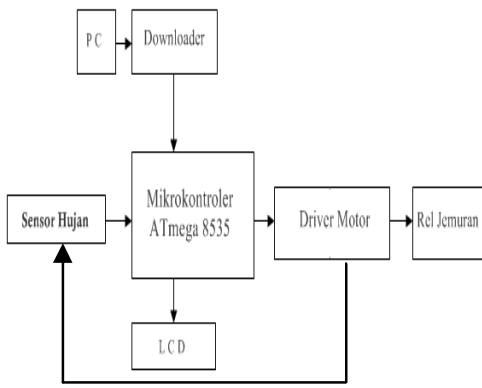

Gambar 3.2. Blok Rancangan Sistem

Penjelasan dari blog rancangan sistem tersebut adalah, Untuk menjalankan actuator, sensor hujan mendeteksi ada atau tidaknya air yang diterima oleh sensor hujan. Apabila sensor hujan mendeteksi adanya air, maka rangkaian sensor akan memberi perintah pada mikrokontroler untuk menghidupkan motor yang akan menggerakan jemuran masuk ruangan. Setelah jemuran masuk, motor akan berhenti dengan sendiri saat microswitch yang dipasang pada ujung rel jemuran tersentuh oleh jemuran.

Apabila sensor tidak mendeteksi adanya air, maka sensor akan memberi perintah pada mikrokontroler untuk menghidupkan motor yang akan menggerakan jemuran keluar ruangan. Motor akan berhenti dengan sendiri apabila jemuran sudah keluar dari dalam ruangan setelah microswitch tertsentuh oleh jemuran.

Layar $L C D$ akan menampilkan semua proses yang dilakukan oleh mikrokontroler, baik saat mendeteksi cuaca cerah ataupun hujan $L C D$ akan menampilkan semua kondisi yang terjadi.

\subsubsection{Perancangan Perangkat Keras}

Rangkaian yang digunakan dalam perancangan hardware antara lain adalah:

1. Power supply

Power supply umumnya dipakai pada rangkaian listrik yang bertegangan rendah. Dan dalam penelitian tugas akhir ini power suppy dipakai sebagai sumber tegangan untuk rangkaian mikrokontroller dan rangkaian sensor. 


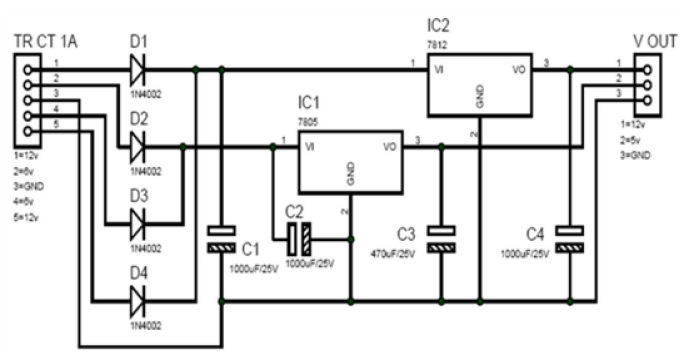

Gambar 3.3.Rangkaian Power Supply

\section{Sensor}

Alat yang digunakan sebagai sensor dalam tugas akhir ini menggunakan sensor hujan, gambar sensor tersebut adalah sebagai berikut :

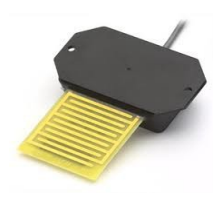

Gambar 3.4 Sensor Hujan

Sensor hujan akan digunakan untuk memberikan input pada mikrokontroler. Setelah mikrokontroler mendapat input maka mikrokontroler akan memberikan keluaran yang akan diterima oleh rangkaian driver motor yang akan memerintahkan motor untuk berputar ke kanan atau ke kiri.

\section{Perancangan Mekanik}

Pada perancangan mekanik terdiri dari perencanaan desain mekanik perangkat keras yang mendukung kinerja. Pembuatan perangkat mekanik terdiri dari perencanaan desain mekanis yang mendukung kinerja alat dan berkarakter sesuai pada kondisi sesungguhnya. Perencanaan ini terdiri dari pengaturan peletakan posisi sensor hujan, $L C D$, rel sebagai tempat jemuran, motor sebagai penggerak rel

\section{Rangkaian Pengendali}

Rangkaian pengendali atau control berfungsi untuk mengendalikan kerja dari rangkaian jemuran otomatis. Rangkaian control ini menggunakan mikrokontroler ATMega8535 yang memiliki fitur membaca nilai output dari rangkaian sensor hujan yang akan dijadikan nilai 1 atau 0 .

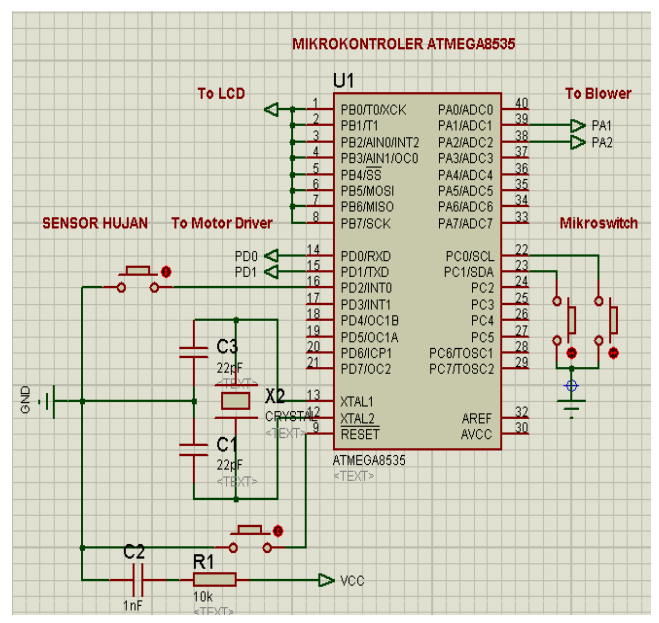

Gambar 3.5 . Rangkaian Mikrokontroller Dengan Pin Input Dan Output

Input yang diberikan pada rangkaian mikrokontroler berasal dari sensor hujan yang dimana sensor hujan hujan akan memberikan nilai 0 atau 1 yang akan menjadi masukan untuk mikrokontroler.

\section{Liquid Crystal Display ( LCD )}

Gambar dibawah menunjukan bentuk rangkaian skematik dari $L C D$

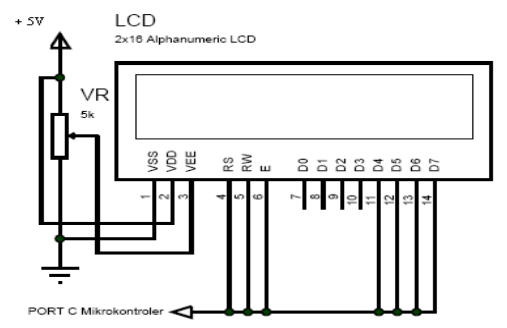

Gambar 3.6Rangkaian Skematik LCD

$L C D$ digunakan sebagai penampil keadaan cuaca apakah hujan atau cerah, selain itu $L C D$ juga dipakai untuk melihat keadaan jemuran, apakah motor bekerja atau tidak saat terjadi turun hujan atau hujan sudah reda.

\section{Driver motor}

Driver motor digunakan untuk memutar balik putaran motor. Driver motor diperlukan untuk menggerakan piranti yang lebih besar, dikarenakan 
output dari Port input-output mikrokontroler hanya memberikan arus sebesar $20 \mathrm{~mA}$.

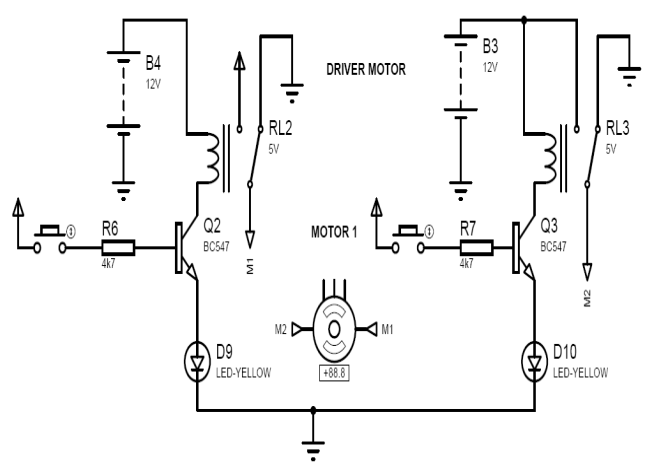

Gambar 3.7. Driver Motor DC

\subsubsection{Perancangan Perangkat Lunak.}

Pembuatan program data pada mikrokontroller adalah menuliskan kode atau perintah pada mikrokontroler ATmega 8535, penulisan perintah ini menggunakan bahasa pemrograman $\mathrm{C}$ pada software Code Vision AVR. Program data yang direncanakan untuk mikrokontroler ATMega8535 pada tugas akhir ini mempunyai fungsi sebagai berikut :

1. Menerima input dari sensor hujan

2. Memproses sinyal input dari sensor hujan

3. Nilai output dari rangkaian sensor hujan, selanjutnya akan diterima oleh Pin input pada mikrokontroler dan mikrokontroler akan memberikan nilai output pada PORD.O dan PORTD.1 dari mikrokontroller dan menjadi nilai masukan bagi rangkaian driver motor.

\subsubsection{Pengujian Alat}

Pengujian alat dilakukan secara bertahap, dari rangkaian power supply, rangkaian sensor hujan, rangkaian mikrokontroller dan rangkaian driver motor. Pengujian secara bertahap ini dimaksudkan agar mengetahui bagian-bagian yang tidak bekerja. Dan kemudian dapat diperbaiki secara secara terpisah pada tiap-tiap bagian. Jika semua bagian rangkaian bekerja dengan baik maka semua rangkaian dipasang secara keseluruhan, agar bisa diketahui apakah rangkaian jemuran otomatis ini dapat bekerja dengan baik atau tidak.

\section{HASIL DAN PEMBAHASAN}

\subsection{Proses Kerja Penjemur Pakaian Otomatis Berbasis Mikrokontroler ATmega8535.}

Penjemur pakaian otomatis bekerja berdasarkan input dari sensor hujan yang diletakan diatas rumah jemuran otomatis. Sensor hujan akan memberikan nilai output high saat terkena air dan low pada saat tidak terkena air, yang dimana logika high dan low tersebut akan menjadi input bagi mikrokontroler sebagai pengendali utama untuk memberikan perintah pada driver motor.

Driver motor digunakan untuk menggerakan motor berputar kekanan atau kekiri berdasarkan input dari mikrokontroler. Selain itu driver motor juga digunakan untuk mengendalikan kecepatan putaran motor. Pada saat motor berputar kekanan ataupun kekiri jemuran akan bergerak mengikuti arah putaran motor, dan jemuran akan berhenti dengan sendirinya saat menyentuh microswitch yang ada pada ujung rel jemuran yang berfungsi sebagai saklar untuk memerintahkan mikrokontroler untuk menghentikan perintah pada driver motor.

Pada saat sensor hujan mendeteksi adanya air, blower juga akan hidup yang dimana akan meniupkan udara yang dapat membantu mengeringkan pakaian.

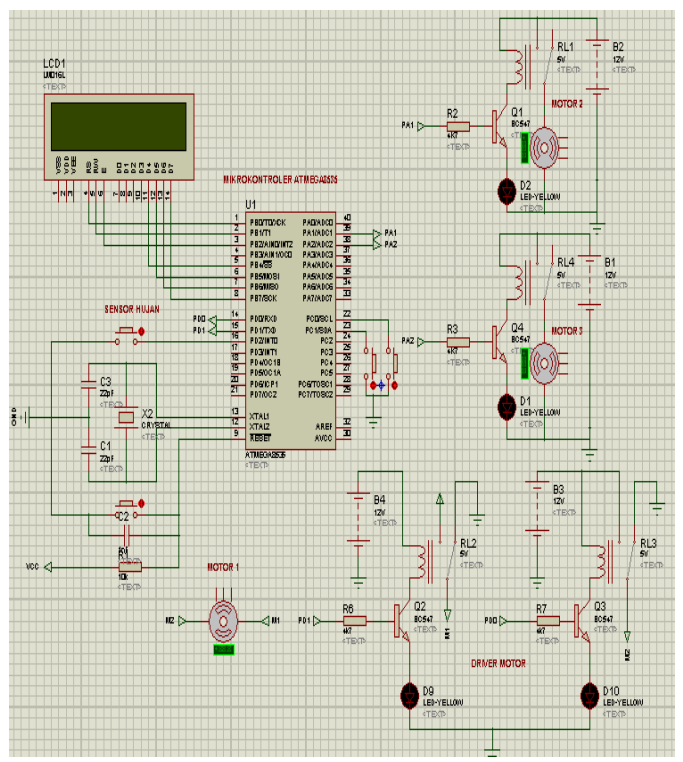

Gambar 4.1. Rangkaian Skematik Sistem

Gambar diatas merupakan rangkaian skematik dari keseluruhan sistem yang terdiri dari, sensor, rangkaian pengendali, driver motor dan LCD. Dimana semua kondisi keadaan yang terjadi dapat ditampilkan pada layar LCD. 
4.2 Pengoperasian alat ini secara keseluruhan adalah sebagai berikut:

1. Yang pertama harus dilakukan adalah dengan merangkai terlebih dahulu semua alat ini menjadi satu-kesatuan dan siap untuk dioperasikan. Berikut adalah gambar dari keseluruhan alat yang siap untuk dioperasikan.

\section{Gambar 4.2. Penjemur Pakaian Otomatis}

2. Setelah semua alat terangkai, hidupkan power supply yang menjadi sumber tegangan utama. Setelah power supply hidup, rangkaian keseluruhan akan aktif, dan pada saat itu juga sensor akan mendeteksi keadaan cuaca yang sedang terjadi.

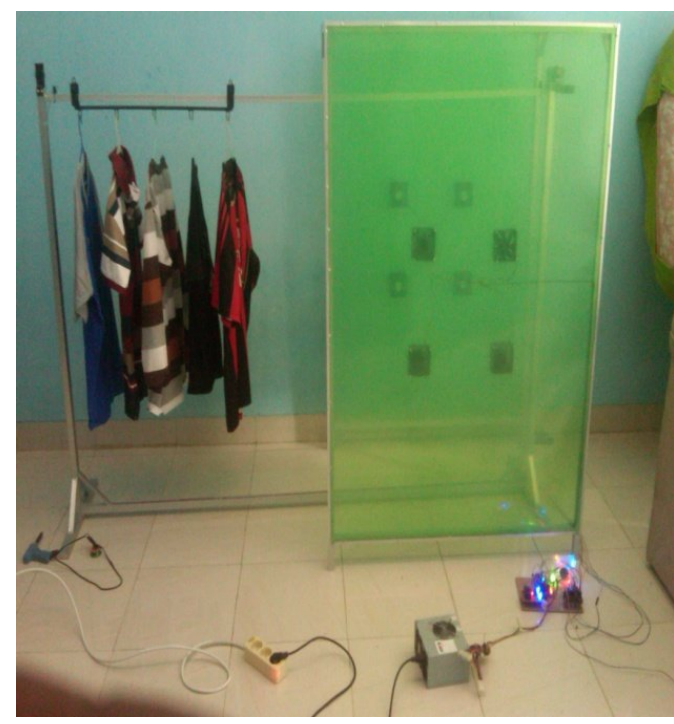

3. Pada saat sensor tidak mendeteksi adanya air yang berarti cuaca tidak dalam keadaan hujan, maka motor akan menggerakan rel jemuran keluar secara otomatis sesuai dengan program yang telah didownload pada mikrokontroler. Dan jemuran akan berhenti dengan sendirinya setelah rel jemuran menyentuh microswitch yang telah dipasang pada rel jemuran.

4. Pada saat sensor mendeteksi adanya air yang berarti cuaca dalam keadaan hujan, maka motor akan bekerja menggerakan rel jemuran masuk secara otomatis sesuai dengan program yang telah didownload pada mikrokontroler. Dan jemuran akan berhenti dengan sendirinya setelah rel jemuran menyentuh microswitch yang telah dipasang pada rel jemuran bagian dalam.
5. Pada saat jemuran masuk kedalam ruangan, mikrokontroler akan memerintahkan blower untuk hidup agar dapat membantu mengeringkan pakaian yang masih basah. Blower akan mati secara otomatis apabila sensor mendeteksi cuaca tidak dalam keadaan hujan.

\subsection{Perhitungan yang dilakukan dalam pembuatan alat ini adalah sebagai berikut:}

a. Perhitungan menetukan resistor pada rangkaian pemicu.

Nilai R2,R3,R6,R7 pada rangkaian memiliki nilai yang sama dan berikut adalah contoh perhitungan untuk menentukan besar $\mathrm{R}$ pada setiap rangkaian:

\section{Dik IB max : 0,2 A \\ : $\quad$ VBE : $0,7 \mathrm{~V}$ \\ $\mathrm{VBB}: 5 \mathrm{~V}$}

Dit : RB ...?

Penyelesaian:

$$
\begin{gathered}
I B=\frac{V B B-V B E}{R E} \\
0,2=\frac{5{ }^{0,7}}{R B} \\
0,2=\frac{4,3}{R B} \\
R B=\frac{4,3}{0,2} \\
R E=21,5 \Omega
\end{gathered}
$$

Untuk mendapatkan IB sebesar 0,2 A, maka pada rangkaian harus dipasang resistor sebesar 21,5 $\Omega$, ataupun resistor dengan nilai lebih besar dari 21,5 $\Omega$ karena IB maksimum adalah 0,2 A, jika dipasang resistor lebih kecil maka IB akan lebih besar dari 0,2 A. dan menyebabkan transistor BC547 tidak bekerja dengan baik dan dapat menyebabkan rangkaian tidak bekerja secara maksimal.

b. Perhitungan daya motor .

Perhitungan daya motor yang digunakan untuk menggerakkan jemuran yaitu dengan menggunakan rumus perhitungan daya motor sebagai berikut,

$$
\begin{array}{cl} 
& \multicolumn{1}{c}{\mathrm{P}=\mathrm{V} \times \mathrm{I}(\mathrm{W})} \\
\text { Dimana } & \mathrm{P}=\text { Daya motor }(\mathrm{W}) \\
& \mathrm{V}=\text { Tegangan } \operatorname{Kerja} \operatorname{Motor}(\mathrm{V}) \\
\mathrm{I}=\text { Arus Kerja } \operatorname{Motor}(\mathrm{A})
\end{array}
$$


Diketahui bahwa, $\mathrm{V}=12 \mathrm{~V}$ dan $\mathrm{I}=5 \mathrm{~A}$

Maka, $\mathrm{P}=12 \times 5=60 \mathrm{Watt}$

Jadi daya motor yang digunakan untuk pembuatan alat ini adalah 60 Watt.

\section{KESIMPULAN DAN SARAN}

\subsection{Kesimpulan}

Berdasarkan hasil pengujian dan pembahasan dapat ditarik simpulan sebagai berikut :

1. Telah berhasil membuat alat penjemur pakaian otomatis berbasis mikrokontroler atmega8535.

2. Penjemur Pakaian Otomatis Berbasis Mikrokontroler Atmega8535 dapat digunakan untuk memperingan pekerjaan rumah tangga yaitu menjemur pakaian

3. Mikrokontroler ATmega8535 yang digunakan sebagai pengendali utama dalam alat ini dapat bekerja dengan baik dalam menjalankan setiap program atau perintah yang diberikan.

\subsection{Saran}

1. Untuk dapat menjemur pakaian yang lebih banyak sebaiknya digunakan motor DC dengan torsi yang lebih besar.

2. Tali penggulung jemuran sebaiknya menggunakan tali yang lebih kuat agar dapat memastikan bahwa jemuran sudah tergulung dengan baik.

3. Sensor yang dipasang harus lebih dari satu dengan tujuan apabila terjadi turun hujan sensor akan mendeteksi hujan lebih cepat

\section{Daftar Pustaka}

[1] Heryanto Ary, Adi Wisnu P. 1991. pemroggraman Bahasa C Untuk Mikrokontroller Atmega8535.Andi. Yogyakarta.

[2] Setyawan, FX Arinto.,Sulistiyanti, Sri Ratna. 2006. Dasar Sistem Kendali ELT 307. Universitas Lampung. Lampung.

[3] Zuhal.1995. Dasar Teknik Tenaga Listrik dan Elektonika Daya. Gramedia Pustaka Utama, Jakarta. 